\title{
Expression of PD-1, PD-L1 and PD-L2 is associated with differentiation status and histological type of endometrial cancer
}

\author{
ZHONGFU MO ${ }^{1,2^{*}}$, JING LIU $^{1,2^{*}}$, QIUYANG ZHANG ${ }^{2}$, ZHIQUAN CHEN ${ }^{2,3}$, JIANDONG MEI $^{2,4,5}$, \\ LUNXU LIU ${ }^{4,5}$, SHIJIE YANG ${ }^{2,6}$, HUINA LI ${ }^{7}$, LIFEI ZHOU ${ }^{1}$ and ZONGBING YOU ${ }^{2}$
}

${ }^{1}$ Department of Obstetrics and Gynecology, Shijiazhuang Maternal and Child Health Care Hospital, Shijiazhuang,

Hebei 050000, P.R. China; ${ }^{2}$ Department of Structural and Cellular Biology, Tulane University, New Orleans, LA 70112, USA; ${ }^{3}$ Department of Thoracic Surgery, Affiliated Hospital of North China University of Science and Technology,

Tangshan, Hebei 063000; ${ }^{4}$ Department of Thoracic Surgery, West China Hospital, Sichuan University;

${ }^{5}$ Western China Collaborative Innovation Center for Early Diagnosis and Multidisciplinary Therapy of Lung Cancer, Sichuan University, Chengdu, Sichuan 610041; ${ }^{6}$ Department of Urology, The Third Hospital of Hebei Medical University, Shijiazhuang, Hebei 050011; ${ }^{7}$ Department of Pathology, Shijiazhuang Maternal and Child Health Care Hospital, Shijiazhuang, Hebei 050000, P.R. China

Received December 8, 2015; Accepted May 26, 2016

DOI: $10.3892 / 01.2016 .4744$

\begin{abstract}
Endometrial cancer (EC) is the most frequent gynecological malignancy and a major cause of morbidity and mortality for women worldwide. Programmed cell death protein 1 (PD-1) and its ligands programmed death ligand 1 (PD-L1) and programmed death ligand 2 (PD-L2) have been well studied in lung cancer, melanoma and renal-cell cancer. However, few studies have been performed in EC. The purpose of the present study was to assess the expression of PD-1, PD-L1 and PD-L2 in 35 human normal endometrial tissue samples and 75 human EC tissue samples using immunohistochemical staining. It was found that $61.3 \%$ of ECs were positive for PD-1 staining, which was almost exclusively found in the tumor-infiltrating immune cells. By contrast, PD-1 was not expressed in the tumor cells or normal endometrial tissues. It was also found that $14.3 \%$ of normal endometria and $17.3 \%$ of EC tissues were positive for PD-L1 expression, while $20.0 \%$ of normal endometrium and $37.3 \%$ of EC tissues were positive for PD-L2 expression; however, there was no statistically significant difference between the normal endometrium and EC tissues. PD-1 expression in the tumor-infiltrating immune cells was more frequently found in the moderately and poorly-differentiated ECs and non-endometrioid (type II) ECs than in the well-differentiated ECs and endometrioid (type I) ECs. Similarly, PD-L1 and
\end{abstract}

Correspondence to: Dr Zongbing You, Department of Structural and Cellular Biology, Tulane University, Mailbox 8649, 1430 Tulane Avenue, New Orleans, LA 70112, USA

E-mail: zyou@tulane.edu

${ }^{*}$ Contributed equally

Key words: endometrial cancer, immunohistochemistry, PD-1, PD-L1, PD-L2
PD-L2 expression in the tumor-infiltrating immune cells was more frequently found in the moderately and poorly-differentiated ECs and type II ECs than in the type I ECs. The present findings indicate a possible better outcome for future treatment with anti-PD-1 or anti-PD-L1 antibody-based therapies against these subgroups of endometrial cancers with frequent expression of the PD-1/PD-L1/PD-L2 axis.

\section{Introduction}

Endometrial cancer (EC) is the most common gynecological malignancy, with almost 200,000 cases diagnosed every year, and is a major cause of morbidity and mortality for women worldwide $(1,2)$. EC has been broadly classified into two types, termed type I and type II, which possess different etiologies and patient survival rates (3). Type I EC includes endometrioid adenocarcinomas that represent $80-90 \%$ of EC arising from atypical endometrial hyperplasia with unopposed estrogen exposure $(4,5)$. The remaining $10-20 \%$ of EC are classified as type II, including papillary serous EC, clear cell EC and other histological variants. Type II ECs are mostly poorly-differentiated, estrogen-independent and aggressive, with a $~ 50 \%$ recurrence rate and mortality rate of 50-60\% of patients with stage I-II disease (6). The majority of EC patients are diagnosed at an early stage and are treated by surgery with favorable outcomes. However, certain women are diagnosed at a late stage or with type II EC, and often suffer from worse outcomes with limited adjuvant treatment options and low survival rates, for example, patients with low-grade (well-differentiated) type I ECs have a 5-year survival rate of $\sim 90 \%$, whereas patients with high-grade (poorly-differentiated) type I ECs have a 5-year survival rate of 45-77\% (6-10). By contrast, patients with type II ECs, including papillary serous and clear cell ECs, have a 5-year survival rate of $35-53 \%(4,6)$.

Previous studies have identified certain risk factors for EC, such as nulliparity, early age at menarche, late age at menopause, 
unopposed estrogen treatment, hereditary non-polyposis colorectal cancer and polycystic ovarian syndrome $(11,12)$. However, EC pathogenesis remains poorly understood. Additional attention has been paid to the tumor microenvironment and mechanisms of immune evasion. For example, programmed cell death protein 1 (PD-1) has emerged as a key player in tumor immune evasion. PD-1 is a member of the B7/cluster of differentiation (CD)28 family, which is an immune check-point receptor expressed on $\mathrm{T}$ cells, natural killer cells, monocytes and B cells (13-15). The ligands for PD-1, namely, programmed death ligand 1 (PD-L1) and programmed death ligand 2 (PD-L2), interact with PD-1 to suppress T cell functions and induce tumor immune evasion (16). PD-L1 is expressed by tumor cells and tumor-infiltrating immune cells, including macrophages, dendritic cells and T cells (17). PD-L1 and PD-L2 mRNAs are found in human heart, placenta, spleen, lymph node and thymus tissues. Additionally, PD-L2 mRNA, but not PD-L1 mRNA, is found in human lung, liver, smooth muscle and pancreas tissues (18). In the tumor microenvironment, the PD-1/PD-L1/PD-L2 immune inhibitory pathway plays a pivotal role in the ability of tumor cells to evade the host's immune system by inhibiting cytotoxic $\mathrm{T}$ lymphocyte proliferation, inducing apoptosis of infiltrating $\mathrm{T}$ cells, and increasing the amount of regulatory $\mathrm{T}$ cells $(19,20)$. Based on the understanding of the immunosuppressive function of the PD-1/PD-L1/PD-L2 axis, multiple clinical trials have demonstrated that antibodies against PD-1 or PD-L1 are effective therapeutics to block immune evasion and induce tumor regression in patients with melanoma, non-small cell lung cancer, and renal-cell cancer (21-27). Therefore, the US Food and Drug Administration (FDA) has approved the anti-PD-1 antibodies pembrolizumab (Keytruda ${ }^{\circledR}$; Merck \& Co., Inc., Kenilworth, NJ, USA) (28) and nivolumab (Opdivo ${ }^{\circledR}$; Bristol-Myers Squibb, Princeton, NJ, USA) (29) for the treatment of patients with unresectable or metastatic melanoma. Nivolumab has also been approved for the treatment of patients with metastatic squamous non-small cell lung cancer, with progression on or after platinum-based chemotherapy (30). The FDA has assigned a priority review designation to pembrolizumab as a treatment for patients with advanced non-small cell lung cancer (31). Since the anti-PD-L1 antibody MPDL3280A (Genentech, Inc., South San Francisco, CA, USA) showed responsive rates of $13-26 \%$ in solid tumors, including non-small cell lung cancer (17), the FDA has assigned MPDL3280A a breakthrough therapy designation for the treatment of PD-L1-positive non-small cell lung cancer that has progressed during or subsequent to platinum-based chemotherapy, as well as a targeted therapy for patients with epidermal growth factor receptor-positive or anaplastic lymphoma kinase-positive tumors, pending the outcomes of ongoing phase II and III trials (32).

There have been an extremely limited number of studies on PD-1 and EC $(33,34)$, and neither of the previous two studies has addressed the association between PD-1 expression and clinicopathological characteristics of EC patients. Therefore, the aim of the present study was to assess expression of PD-1, PD-L1 and PD-L2 in EC and to compare the expression of these proteins with clinicopathological characteristics. Immunohistochemical (IHC) staining was performed in 35 normal endometrium tissues and 75 EC tissues. It was found that PD-1 expression was significantly increased in EC than in normal endometrium and that expression of PD-1, PD-L1 and PD-L2 in the tumor-infiltrating immune cells was associated with differentiation status and histological type of EC.

\section{Materials and methods}

Human endometrial tissue samples. In total, 35 samples of normal endometrium and 75 samples of ECs that were archived from surgeries performed between January 2012 and December 2014, in the Department of Obstetrics and Gynecology at Shijiazhuang Maternal and Child Health Care Hospital and the Department of Obstetrics and Gynecology at Shijiazhuang First Hospital (Shijiazhuang, Hebei, China) were retrospectively collected. The samples were formalin-fixed and paraffin-embedded tissue blocks and the pathological diagnoses were re-confirmed by a pathologist. The present study was approved by the Institutional Review Boards of Shijiazhuang Maternal and Child Health Care Hospital and Shijiazhuang First Hospital. The procedures to obtain human endometrial tissues were in accordance with the Ethical Principles for Medical Research Involving Human Subjects, as formulated in the World Medical Association Declaration of Helsinki (2008 revision). The clinicopathological characteristics of the patients were summarized in Table I.

Immunohistochemistry. Tissue sections (4- $\mu$ m thick) were baked at $60^{\circ} \mathrm{C}$ for $60 \mathrm{~min}$, deparaffinized in xylene and rehydrated through graded ethanol solutions to water. The antigens were retrieved by heating the tissue sections in $0.01 \mathrm{M}$ ethylenediaminetetraacetic acid buffer at $95^{\circ} \mathrm{C}$ for $5 \mathrm{~min}$ and then cooling down to room temperature for $20 \mathrm{~min}$. Endogenous peroxidase activity was blocked by $0.3 \% \mathrm{H}_{2} \mathrm{O}_{2}$ for $5 \mathrm{~min}$. Non-specific binding was blocked with $1.5 \%$ normal goat or horse serum (VECTASTAIN Elite ABC kit; Vector Laboratories, Burlingame, CA, USA). The tissue sections were incubated with primary antibodies in a humid chamber at $4^{\circ} \mathrm{C}$ overnight. Rabbit anti-human PD-L1 polyclonal antibodies (dilution, 1:400; catalog no., ab58810; Abcam, Cambridge, MA, USA), rabbit anti-human PD-L2 polyclonal antibodies (dilution, 1:800; catalog no., SAB3500395-100UG; Sigma-Aldrich, St. Louis, MO, USA), and rabbit anti-human CD279 (PD-1) affinity-purified and validated polyclonal antibodies (dilution, 1:600; catalog no., PIPA520351; Fisher Scientific; Thermo Fisher Scientific, Inc., Waltham, MA, USA) were used as the primary antibodies. Subsequent to being washed 3 times in phosphate-buffered saline, the tissue sections were incubated with goat anti-rabbit polyclonal secondary antibodies (dilution, 1:200; catalog no., PK-6101; VECTASTAIN Elite ABC kit; Vector Laboratories) for $2 \mathrm{~h}$ at room temperature. The color was developed using 3,3'-diaminobenzidine substrate kit (Vector Laboratories) following the manufacturer's protocol. The tissue sections were then counterstained with hematoxylin. The tissue sections that had previously stained positively for PD-1, PD-L1 and PD-L2 in a pilot study were used as positive controls and the tissue sections stained with non-immune serum (Vector Laboratories) acted as negative controls. Positive staining for PD-1, PD-L1 and PD-L2 appeared as brown particles at the cytoplasmic membrane or in the cytoplasm. Under microscopy, 5 representative high-power fields (x400 magnification) per tissue section were randomly selected and evaluated by two investigators, who were blinded 
Table I. Clinicopathological characteristics of patients.

\begin{tabular}{lc}
\hline Characteristics & Number \\
\hline Normal endometrium & 35 \\
Age, mean \pm SD (years) & $45.3 \pm 5.6$ \\
Endometrial cancer & 75 \\
Age, mean \pm SD (years) & $57.3 \pm 10.1$ \\
<60 years & 45 \\
$\geq 60$ years & 30 \\
Differentiation & \\
Well & 37 \\
Moderate & 23 \\
Poor & 15 \\
Stage & \\
I & 62 \\
II & 4 \\
III & 9 \\
Histological type & \\
Endometrioid & 63 \\
Papillary serous & 11 \\
Clear cell & 1 \\
Vascular invasion & \\
Yes & \\
No & \\
\hline
\end{tabular}

$\mathrm{SD}$, standard deviation.

to the clinicopathological data. An average of the scores obtained by the two examiners was used to represent each case. A two-score system based on a proportion score and an intensity score was used, as previously described by Allred et al (35). The proportion scores indicated the proportion of positive staining: 0 , None; 1 , less than one-hundredth; 2, one-hundredth to one-tenth; 3, one-tenth to one-third; 4, one-third to two-thirds; and 5, greater than two-thirds. The intensity scores represented the estimated average staining intensity of positive staining: 0 , None; 1, weak; 2, intermediate; and 3, strong. The overall scores (Allred scores) were the sum of the proportion score and intensity score of each case (range, 0-8).

Statistical analysis. Statistical analysis was performed using SPSS version 16.0 for Windows (SPSS, Inc., Chicago, IL, USA). Patient age was expressed as mean \pm standard deviation. The comparison of clinicopathological characteristics between different groups was performed using the $\chi^{2}$ test. Spearman's correlation coefficient was calculated to reveal the correlation between PD-1 scores and PD-L1 or PD-L2 scores. P $<0.05$ was considered to indicate a statistically significant difference.

\section{Results}

PD-1, PD-L1 and PD-L2 are expressed in endometrial cancer. IHC staining for PD-1, PD-L1 and PD-L2 was performed using 35 normal endometrium tissues and 75 EC tissues. Representative photomicrographs of the stained samples are shown in Fig. 1. Any sample was defined as having positive staining if the Allred score was $\geq 1$ and any sample was defined as having negative staining if the Allred score was 0 . It was found that all normal endometrial samples were negative for PD-1 expression, whereas $61.3 \%$ of ECs were positive for PD-1 staining (Table II; $\mathrm{P}<0.001)$. In total, $14.3 \%$ of normal endometrial samples were positive for PD-L1 staining, while $17.3 \%$ of ECs were positive for PD-L1 staining (Table II; P=0.687). In addition, $20.0 \%$ of normal endometrial samples were positive for PD-L2 staining, while $37.3 \%$ of ECs were positive for PD-L2 staining (Table II; $\mathrm{P}=0.069$ ). It was found that PD-1 was only expressed in the tumor-infiltrating immune cells, but not in the tumor cells (Fig. 1). By contrast, PD-L1 and PD-L2 were expressed in the tumor cells and infiltrating immune cells (Fig. 1).

PD-1 expression is associated with differentiation status and histological type of EC. As shown in Table III, the rate of positive PD-1 staining was $73.7 \%$ in the poorly and moderately-differentiated ECs, which was significantly increased compared with the well-differentiated ECs $(48.6 \%$; $\mathrm{P}=0.026)$. The rate of positive PD-1 staining was $100 \%$ in the non-endometrioid ECs, including 11 papillary serous ECs and 1 clear cell EC, which was significantly increased compared with the endometrioid ECs (54.0\%; P=0.006; Table III). However, PD-1 expression was not different among patients with different ages, clinical stages or statuses of vascular invasion in the tumors (Table III).

PD-L1 expression in the tumor-infiltrating immune cells is associated with the differentiation status and histological type of EC. As shown in Table IV, the rate of positive PD-L1 staining in the tumor-infiltrating immune cells was $\sim 73.7 \%$ in the poorly and moderately-differentiated ECs, which was significantly increased compared with the well-differentiated ECs (45.9\%; $\mathrm{P}=0.014)$. The rate of positive PD-L1 staining in the tumor-infiltrating immune cells was $100 \%$ in the non-endometrioid ECs, which was significantly increased compared with in the endometrioid ECs $(52.4 \%$; $\mathrm{P}=0.006$; Table IV). However, PD-L1 expression in the tumor-infiltrating immune cells was not different among patients with different ages, clinical stages or statuses of vascular invasion in the tumors (Table IV). In addition, PD-L1 expression in the tumor cells was not significantly different among patients with different ages, differentiation statuses, clinical stages, histological types or statuses of vascular invasion in the tumors (Table IV).

PD-L2 expression in the tumor-infiltrating immune cells is associated with the differentiation status and histological type of EC. As shown in Table V, the rate of positive PD-L2 staining in the tumor-infiltrating immune cells was $73.7 \%$ in the poorly and moderately-differentiated ECs, which was significantly higher than in the well-differentiated ECs $(51.4 \%$; $\mathrm{P}=0.046)$. The rate of positive PD-L2 staining in the tumor-infiltrating immune cells was $100 \%$ in the non-endometrioid ECs, which was significantly higher than in the endometrioid ECs (55.6\%; $\mathrm{P}=0.003$; Table V). However, PD-L2 expression in the tumor-infiltrating immune cells was not significantly different among patients with different ages, clinical stages or statuses of vascular invasion in the tumors (Table V). Additionally, PD-L2 expression in the tumor cells was not significantly different among patients with different 
Table II. Expression of PD-1, PD-L1 and PD-L2 in normal endometrium and EC.

\begin{tabular}{|c|c|c|c|c|c|c|c|}
\hline \multirow[b]{2}{*}{ Group } & \multirow[b]{2}{*}{$\mathrm{n}$} & \multicolumn{2}{|c|}{ PD-1 } & \multicolumn{2}{|c|}{ PD-L1 } & \multicolumn{2}{|c|}{ PD-L2 } \\
\hline & & Positive, n (\%) & P-value & Positive, n (\%) & P-value & Positive, n (\%) & P-value \\
\hline Normal & 35 & $0(0.0)$ & $<0.001$ & $5(14.3)$ & 0.687 & $7(20.0)$ & 0.069 \\
\hline $\mathrm{EC}$ & 75 & $46(61.3)$ & & $13(17.3)$ & & $28(37.3)$ & \\
\hline
\end{tabular}

EC, endometrial cancer; PD-1, programmed cell death protein 1; PD-L1, programmed death ligand 1; PD-L2, programmed death ligand 2.

Table III. PD-1 expression and clinicopathological characteristics of patients with endometrial cancer.

\begin{tabular}{lccc}
\hline Characteristics & $\mathrm{n}$ & Positive, n (\%) & P-value \\
\hline Patients & 75 & $46(61.3)$ & - \\
Age & & & \\
$\quad<60$ years & 45 & $26(57.8)$ & 0.439 \\
$\geq 60$ years & 30 & $20(66.7)$ & \\
Differentiation & & & \\
Well & 37 & $18(48.6)$ & 0.026 \\
Poor/moderate & 38 & $28(73.7)$ & \\
Stage & & & 0.204 \\
I & 62 & $36(58.1)$ & \\
II/III & 13 & $10(76.9)$ & \\
Histological type & & & \\
$\quad$ Endometrioid & 63 & $34(54.0)$ & \\
Non-endometrioid & 12 & $12(100.0)$ & \\
Vascular invasion & & & \\
Yes & 7 & $42(61.8)$ & \\
No & 68 & & \\
\hline
\end{tabular}

ages, differentiation statuses, clinical stages, histological types or statuses of vascular invasion in the tumors (Table V).

PD-1 expression is associated with PD-L1 and PD-L2 expression in the tumor cells and infiltrating immune cells. It was found that the PD-L1 and PD-L2 Allred staining scores were higher in the tumor-infiltrating immune cells than the tumor cells alone (Fig. 2). Since PD-1 was only expressed in the tumor-infiltrating immune cells, Spearman's correlation analysis was performed between PD-1 scores and PD-L1 or PD-L2 scores. It was found that the PD-1 score was positively associated with the PD-L1 or PD-L2 score in the tumor cells and infiltrating immune cells (Fig. 2).

\section{Discussion}

The present study found that $61.3 \%$ of human ECs stained positive for PD-1, which was almost exclusively found in the tumor-infiltrating immune cells. By contrast, PD-1 was not expressed in the tumor cells or normal endometrial tissues. It was also found that $14.3 \%$ of normal endometria and $17.3 \%$ of ECs were positive for PD-L1 expression, while $20.0 \%$ of normal endometria and $37.3 \%$ of ECs were positive for PD-L2 expression, though there was no statistically significant difference between normal endometrium and EC. Vanderstraeten et al (34) reported that PD-1 expression was present in all 15 cases of normal endometria, PD-L1 expression was present in $81 \%$ of 16 cases of normal endometria, and PD-L2 expression was present in $47 \%$ of 15 cases of normal endometria. In primary ECs, Vanderstraeten et al found that PD-1 expression was present in $100 \%$ of 30 cases of ECs, PD-L1 expression was present in $83 \%$ of 29 cases of ECs, and PD-L2 expression was present in $40 \%$ of 30 cases of ECs. The discrepancy between the present study and the study by Vanderstraeten et al (34) may be due to different antibodies and IHC protocols used. It may also be due to the different EC patients studied. For example, the study by Vanderstraeten et al included 28 cases of papillary serous and clear cell ECs who were compared with 16 cases of endometrioid ECs (34). By contrast, the present study compared 12 cases of papillary serous and clear cell ECs with 63 cases of endometrioid ECs. Therefore, it is expected that Vanderstraeten et al should find more PD-1, PD-L1 and PD-L2-positive cases than the present study, since the present study showed that non-endometrioid ECs were $100 \%$ positive for PD-1, PD-L1 and PD-L2 expression, if we did not distinguish between the tumor cells and infiltrating immune cells. In addition, Howitt et al (33) reported that PD-1 was overexpressed in tumor-infiltrating lymphocytes of $81 \%$ of polymerase $\varepsilon$-mutated ECs and $28 \%$ of microsatellite-instable ECs. In peritumoral lymphocytes, PD-1 was overexpressed in $90 \%$ of polymerase $\varepsilon$-mutated ECs and $28 \%$ of microsatellite-instable ECs. PD-L1 expression was infrequently noted in the tumor cells, but was common in intraepithelial immune cells and more frequent in polymerase $\varepsilon$-mutated ECs $(39 \%)$ than in microsatellite-instable ECs (13\%; $\mathrm{P}=0.02)$ (33). The present study also showed that PD-L1 and PD-L2 expression was less frequently found in the tumor cells than in the tumor-infiltrating immune cells, which is consistent with the findings of Howitt et al (33).

The present study went beyond the previous two studies $(33,34)$ to show the correlation between the expression of PD-1, PD-L1 and PD-L2 and clinicopathological characteristics of ECs. It was shown that PD-1 expression in the tumor-infiltrating immune cells was more frequently found in the moderately and poorly-differentiated ECs and non-endometrioid (type II) ECs than in the well-differentiated ECs and endometrioid (type I) ECs. Similarly, it was shown that PD-L1 and PD-L2 expression in the tumor-infiltrating immune cells was more frequently found in the moderately and poorly-differentiated ECs and non-endometrioid (type II) ECs than in the well-differentiated ECs and endometrioid (type I) 
Table IV. Association between programmed death ligand 1 expression and clinicopathological characteristics of endometrial cancer patients.

\begin{tabular}{|c|c|c|c|c|c|}
\hline \multirow[b]{2}{*}{ Characteristics } & \multirow[b]{2}{*}{$\mathrm{n}$} & \multicolumn{2}{|c|}{ Tumor cells } & \multicolumn{2}{|c|}{ Immune cells } \\
\hline & & Positive, n (\%) & P-value & Positive, n (\%) & P-value \\
\hline Patients & 75 & $13(17.3)$ & - & $45(60.0)$ & - \\
\hline Age & & & 0.681 & & 0.149 \\
\hline$<60$ years & 45 & $7(15.6)$ & & $24(53.3)$ & \\
\hline$\geq 60$ years & 30 & $6(20.0)$ & & $21(70.0)$ & \\
\hline Differentiation & & & 0.141 & & 0.014 \\
\hline Well & 37 & $4(10.8)$ & & $17(45.9)$ & \\
\hline Poor/moderate & 38 & $9(23.7)$ & & $28(73.7)$ & \\
\hline Stage & & & 0.315 & & 0.171 \\
\hline I & 62 & $9(14.5)$ & & 35 (56.6) & \\
\hline II/III & 13 & $4(30.8)$ & & $10(77.0)$ & \\
\hline Histological type & & & 0.237 & & 0.006 \\
\hline Endometrioid & 63 & $9(14.3)$ & & $33(52.4)$ & \\
\hline Non-endometrioid & 12 & $4(33.3)$ & & $12(100.0)$ & \\
\hline Vascular invasion & & & 0.764 & & 0.427 \\
\hline Yes & 7 & $2(28.6)$ & & $3(42.9)$ & \\
\hline No & 68 & $11(16.2)$ & & $42(61.8)$ & \\
\hline
\end{tabular}

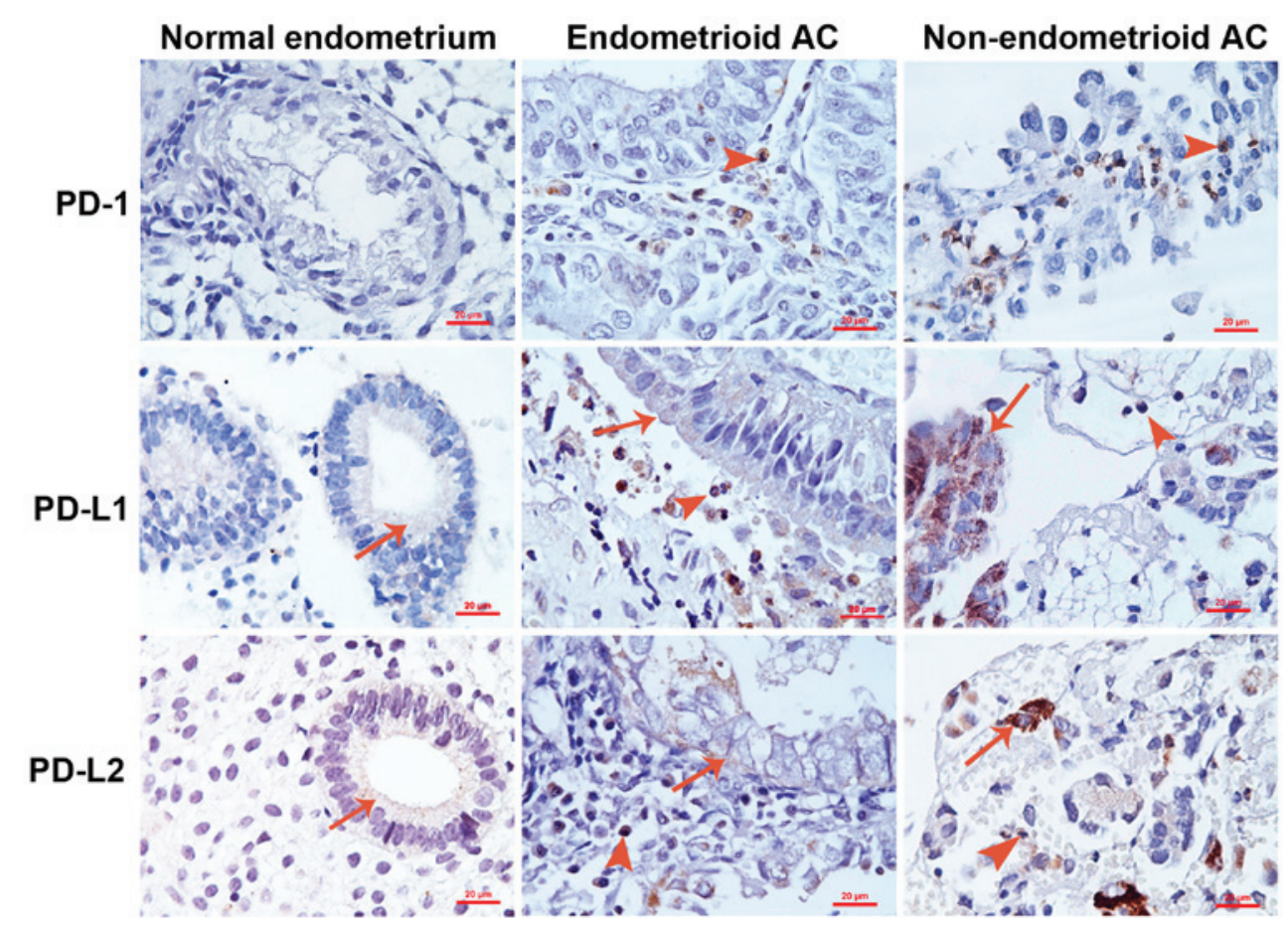

Figure 1. Representative photomicrographs of immunohistochemical staining. Arrows indicate the positively stained normal epithelial or tumor epithelial cells. Arrowheads indicate the positively stained tumor-infiltrating immune cells. Original magnification, x400. Scale bar, $20 \mu \mathrm{m}$. AC, adenocarcinoma; PD-1, programmed cell death protein 1; PD-L1, programmed death ligand 1; PD-L2, programmed death ligand 2.

ECs. It is known that moderately and poorly-differentiated ECs and type II ECs have a lower 5-year survival rate than the well-differentiated ECs and type I ECs (6-10). Therefore, the present findings suggest that more frequent expression of PD-1, PD-L1 and PD-L2 in the moderately and poorly-differentiated
ECs and type II ECs may cause immunosuppression to favor tumor growth, thus negatively affecting the patient's survival. Future studies may address whether expression of PD-1, PD-L1 and PD-L2 may be used as an independent predictor of patient survival, once the follow-up data for the present 
Table V. Association between programmed death ligand 2 expression and clinicopathological characteristics of endometrial cancer patients.

\begin{tabular}{|c|c|c|c|c|c|}
\hline \multirow[b]{2}{*}{ Characteristics } & \multirow[b]{2}{*}{$\mathrm{n}$} & \multicolumn{2}{|c|}{ Tumor cells } & \multicolumn{2}{|c|}{ Immune cells } \\
\hline & & Positive, n (\%) & P-value & Positive, n (\%) & P-value \\
\hline Patients & 75 & $28(37.3)$ & - & $47(62.7)$ & - \\
\hline Age & & & 0.380 & & 0.119 \\
\hline$<60$ years & 45 & $15(33.3)$ & & $25(55.6)$ & \\
\hline$\geq 60$ years & 30 & $13(43.3)$ & & $22(73.3)$ & \\
\hline Differentiation & & & 0.698 & & 0.046 \\
\hline Well & 37 & $13(35.1)$ & & $19(51.4)$ & \\
\hline Poor/moderate & 38 & $15(39.5)$ & & $28(73.7)$ & \\
\hline Stage & & & 1.000 & & 0.393 \\
\hline I & 62 & $23(37.1)$ & & $37(59.7)$ & \\
\hline II/III & 13 & $5(38.5)$ & & $10(76.9)$ & \\
\hline Histological type & & & 0.188 & & 0.003 \\
\hline Endometrioid & 63 & $21(33.3)$ & & $35(55.6)$ & \\
\hline Non-endometrioid & 12 & $7(58.3)$ & & $12(100.0)$ & \\
\hline Vascular invasion & & & 0.095 & & 0.413 \\
\hline Yes & 7 & $5(71.4)$ & & $3(60.0)$ & \\
\hline No & 68 & $23(33.8)$ & & $44(64.7)$ & \\
\hline
\end{tabular}
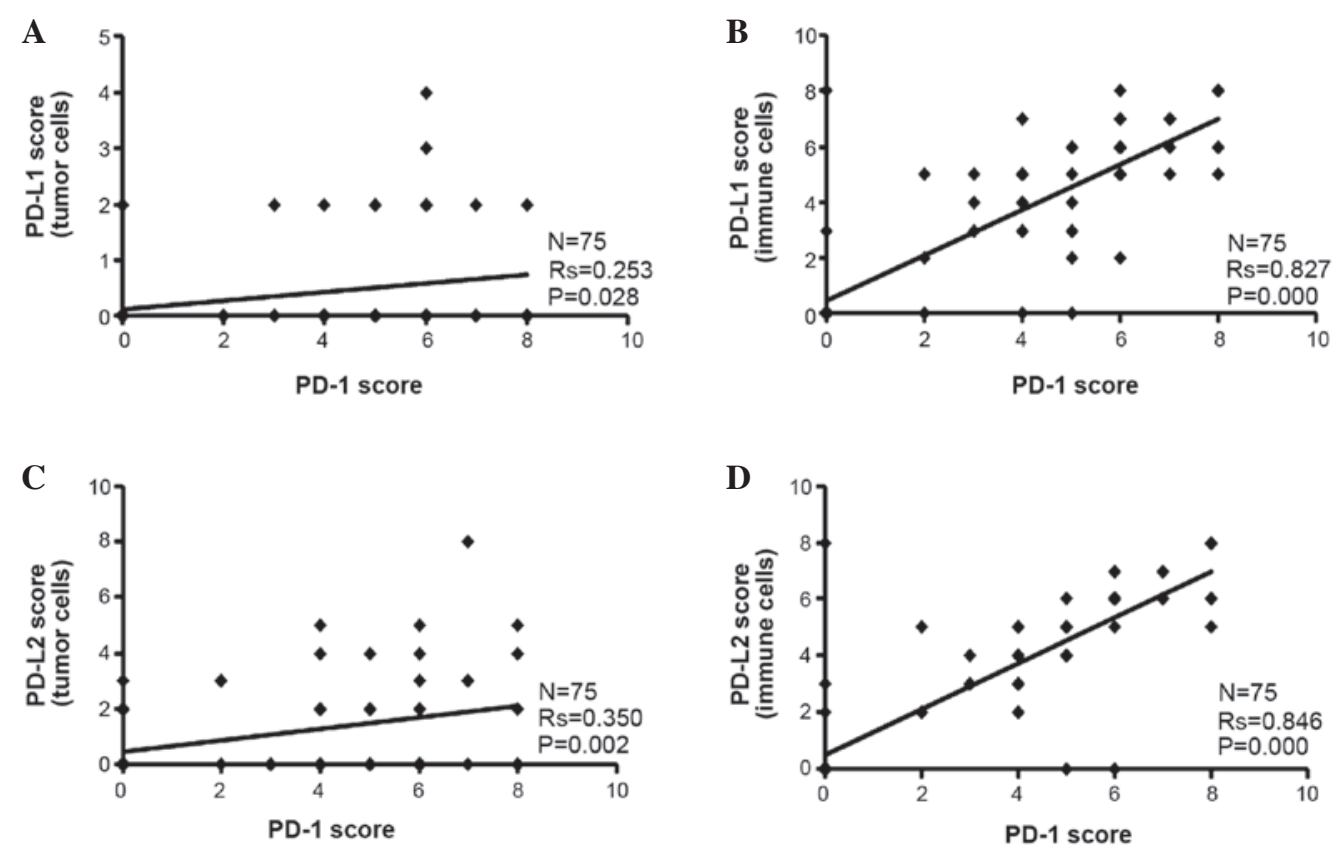

Figure 2. Correlation analysis of PD-1 and PD-L1 or PD-L2 expression. Correlation between PD-1 and PD-L1 scores in the (A) tumor cells and (B) immune cells. Correlation between PD-1 and PD-L2 scores in the (C) tumor cells and (D) immune cells. The expression levels are indicated by Allred scores and assessed by Spearman's correlation coefficient between two proteins. PD-1 expression was only found in the tumor-infiltrating immune cells. PD-L1 and PD-L2 expression was found in the tumor cells and infiltrating immune cells, which was assessed separately. A number of data points are identical, and therefore overlap in each panel. PD-1, programmed cell death protein 1; PD-L1, programmed death ligand 1; PD-L2, programmed death ligand 2.

patients are available. The follow-up data are not available at this time due to the short period subsequent to inclusion of the cases. By contrast, it is reasonable to speculate that the moderately and poorly-differentiated ECs and type II ECs may be more sensitive to anti-PD-1 or anti-PD-L1 antibodies-based therapies, since it has been demonstrated in clinical trials that
PD-L1-positive tumors tend to be more responsive to anti-PD-1 or anti-PD-L1 therapies $(17,26)$.

In summary, the present study demonstrates that the expression of PD-1, PD-L1 and PD-L2 is associated with moderately and poorly-differentiated endometrial cancer and type II endometrial cancer. Frequent expression of the 
PD-1/PD-L1/PD-L2 axis in these subgroups of endometrial cancers may be potentially correlated with their aggressive progression and poor patient survival. The present findings indicate a possible improved outcome for future treatment with Keytruda and Opdivo in these subgroups of endometrial cancers with frequent expression of the PD-1/PD-L1/PD-L2 axis.

\section{Acknowledgements}

Z.Y. was supported partially by National Institutes of Health (grant nos. R01CA174714 and P20GM103518), Department of Defense(grantnos.W81XWH-14-1-0050,W81XWH-14-1-0149, W81XWH-14-1-0458 and W81XWH-15-1-0444), Developmental Fund of Tulane Cancer Center, Louisiana Cancer Research Consortium Fund, and Tulane's Institute of Integrated Engineering for Health and Medicine.Z.M., Z.C. and S.Y. were supported by the Service Center for Experts and Scholars of Hebei Province, China to pursue research in the USA. L.L. was partially supported by National Natural Science Foundation of China (grant nos. NSFC 81172236 and NSFC 81372505) and Key Science and Technology Program of Sichuan Province, China (grant no. 2013SZ0005). J.M. was a visiting scholar at Tulane University School of Medicine sponsored by the China Scholarship Council (grant no. 201406240145).

\section{References}

1. Siegel RL, Miller KD and Jemal A: Cancer statistics, 2015. CA Cancer J Clin 65: 5-29, 2015.

2. Bray F, Loos AH, Oostindier M and Weiderpass E: Geographic and temporal variations in cancer of the corpus uteri: Incidence and mortality in pre- and postmenopausal women in Europe. Int J Cancer 117: 123-131, 2005.

3. Bokhman JV: Two pathogenetic types of endometrial carcinoma. Gynecol Oncol 15: 10-17, 1983.

4. Mendivil A, Schuler KM and Gehrig PA: Non-endometrioid adenocarcinoma of the uterine corpus: A review of selected histological subtypes. Cancer Control 16: 46-52, 2009.

5. Rasool N, Fader AN, Seamon L, Neubauer NL, Shahin FA, Alexander HA, Moore K, Moxley K, Secord AA, Kunos C, et al: Stage I, grade III endometrioid adenocarcinoma of the endometrium: An analysis of clinical outcomes and patterns of recurrence. Gynecol Oncol 116: 10-14, 2010.

6. Goff BA, Kato D, Schmidt RA, Ek M, Ferry JA, Muntz HG, Cain JM, Tamimi HK, Figge DC and Greer BE: Uterine papillary serous carcinoma: Patterns of metastatic spread. Gynecol Oncol 54: 264-268, 1994.

7. Hidaka T, Kato K, Yonezawa R, Shima T, Nakashima A, Nagira K, Nakamura T and Saito S: Omission of lymphadenectomy is possible for low-risk corpus cancer. Eur J Surg Oncol 33: 86-90, 2007.

8. Soslow RA, Bissonnette JP, Wilton A, Ferguson SE, Alektiar KM, Duska LR and Oliva E: Clinicopathologic analysis of 187 high-grade endometrial carcinomas of different histologic subtypes: Similar outcomes belie distinctive biologic differences. Am J Surg Pathol 31: 979-987, 2007.

9. Petignat P, Usel M, Gauthier P,Popowski Y, Pelte MF, Bouchardy C and Verkooijen HM: Outcome of uterine clear cell carcinomas compared to endometrioid carcinomas and poorly-differentiated endometrioid carcinomas. Eur J Gynaecol Oncol 29: 57-60, 2008

10. Hamilton CA, Cheung MK, Osann K, Chen L, Teng NN, Longacre TA, Powell MA, Hendrickson MR, Kapp DS and Chan JK: Uterine papillary serous and clear cell carcinomas predict for poorer survival compared to grade III endometrioid corpus cancers. Br J Cancer 94: 642-646, 2006.

11. Brinton LA, Berman ML, Mortel R, Twiggs LB, Barrett RJ, Wilbanks GD, Lannom L and Hoover RN: Reproductive, menstrual, and medical risk factors for endometrial cancer: Results from a case-control study. Am J Obstet Gynecol 167: 1317-1325, 1992.

12. McPherson CP, Sellers TA, Potter JD, Bostick RM and Folsom AR: Reproductive factors and risk of endometrial cancer. The iowa women's health study. Am J Epidemiol 143: 1195-1202, 1996.
13. Ishida $Y$, Agata $Y$, Shibahara $K$ and Honjo T: Induced expression of pd-1, a novel member of the immunoglobulin gene superfamily, upon programmed cell death. EMBO J 11: 3887-3895, 1992.

14. Keir ME, Butte MJ, Freeman GJ and Sharpe AH: Pd-1 and its ligands in tolerance and immunity. Annu Rev Immunol 26: 677-704, 2008.

15. Sharpe AH and Freeman GJ: The b7-cd28 superfamily. Nat Rev Immunol 2: 116-126, 2002.

16. Blank C, Gajewski TF and Mackensen A: Interaction of PD-L1 on tumor cells with PD-1 on tumor-specific T cells as a mechanism of immune evasion: Implications for tumor immunotherapy. Cancer Immunol Immunother 54: 307-314, 2005.

17. Herbst RS, Soria JC, Kowanetz M, Fine GD, Hamid O, Gordon MS, Sosman JA, McDermott DF, Powderly JD, Gettinger SN, et al: Predictive correlates of response to the anti-PD-L1 antibody MPDL3280A in cancer patients. Nature 515: 563-567, 2014.

18. Latchman Y, Wood CR, Chernova T, Chaudhary D, Borde M, Chernova I, Iwai Y, Long AJ, Brown JA, Nunes R, et al: PD-L2 is a second ligand for PD-1 and inhibits T cell activation. Nat Immunol 2: 261-268, 2001.

19. Day CL, Kaufmann DE, Kiepiela P, Brown JA, Moodley ES Reddy S, Mackey EW, Miller JD, Leslie AJ, DePierres C, et al: PD-1 expression on HIV-specific T cells is associated with T-cell exhaustion and disease progression. Nature 443: 350-354, 2006.

20. Okazaki T and Honjo T: PD-1 and PD-1 ligands: From discovery to clinical application. Int Immunol 19: 813-824, 2007.

21. Brahmer JR, Tykodi SS, Chow LQ, Hwu WJ, Topalian SL, Hwu P, Drake CG, Camacho LH, Kauh J, Odunsi K, et al: Safety and activity of anti-PD-L1 antibody in patients with advanced cancer. N Engl J Med 366: 2455-2465, 2012.

22. Garon EB, Rizvi NA, Hui R, Leighl N, Balmanoukian AS, Eder JP, Patnaik A, Aggarwal C, Gubens M, Horn L, et al: Pembrolizumab for the treatment of non-small-cell lung cancer. N Engl J Med 372: 2018-2028, 2015.

23. Hamid O, Robert C, Daud A, Hodi FS, Hwu WJ, Kefford R, Wolchok JD, Hersey P, Joseph RW, Weber JS, et al: Safety and tumor responses with lambrolizumab (anti-PD-1) in melanoma. N Engl J Med 369: 134-144, 2013.

24. Lipson EJ, Sharfman WH, Drake CG, Wollner I, Taube JM, Anders RA, Xu H, Yao S, Pons A, Chen L, et al: Durable cancer regression off-treatment and effective reinduction therapy with an anti-PD-1 antibody. Clin Cancer Res 19: 462-468, 2013.

25. Robert C, Schachter J, Long GV, Arance A, Grob JJ, Mortier L, Daud A, Carlino MS, McNeil C, Lotem M, et al: Pembrolizumab versus ipilimumab in advanced melanoma. N Engl J Med 372: 2521-2532, 2015.

26. Topalian SL, Hodi FS, Brahmer JR, Gettinger SN, Smith DC, McDermott DF, Powderly JD, Carvajal RD, Sosman JA, Atkins MB, et al: Safety, activity, and immune correlates of anti-PD-1 antibody in cancer. N Engl J Med 366: 2443-2454, 2012.

27. Wolchok JD, Kluger H, Callahan MK, Postow MA, Rizvi NA, Lesokhin AM, Segal NH, Ariyan CE, Gordon RA, Reed K, et al: Nivolumab plus ipilimumab in advanced melanoma. N Engl J Med 369: 122-133, 2013.

28. FDA News Release: FDA approves Keytruda for advanced melanoma. http://www.fda.gov/NewsEvents/Newsroom/PressAnnouncements/ucm412802.htm. Accessed January 2016.

29. FDANews Release:FDA approves Opdivototreat advanced formof kidney cancer. http://www.fda.gov/NewsEvents/Newsroom/PressAnnouncements/ucm473971.htm. Accessed January 2016.

30. Nivolumab (Opdivo). http://www.fda.gov/Drugs/InformationOnDrugs/ApprovedDrugs/ucm436566.htm. Accessed January 2016.

31. http://www.onclive.com/web-exclusives/fda-grants-priority-rev iew-to-pembrolizumab-in-lung-cancer. Accessed January 2016.

32. Cha E, Wallin J and Kowanetz M: PD-L1 inhibition with MPDL3280A for solid tumors. Semin Oncol 42: 484-487, 2015.

33. Howitt BE, Shukla SA, Sholl LM, Ritterhouse LL, Watkins JC, Rodig S, Stover E, Strickland KC, D'Andrea AD, Wu CJ, et al: Association of polymerase e-mutated and microsatellite-instable endometrial cancers with neoantigen load, number of tumor-infiltrating lymphocytes, and expression of PD-1 and PD-L1. JAMA Oncol 1: 1319-1323, 2015.

34. Vanderstraeten A, Luyten C, Verbist G, Tuyaerts S and Amant F: Mapping the immunosuppressive environment in uterine tumors: Implications for immunotherapy. Cancer Immunol Immunother 63: 545-557, 2014.

35. Allred DC, Clark GM, Elledge R, Fuqua SA, Brown RW, Chamness GC, Osborne CK and McGuire WL: Association of p53 protein expression with tumor cell proliferation rate and clinical outcome in node-negative breast cancer. J Natl Cancer Inst 85: 200-206, 1993. 